\title{
SWOT Analysis (or SWOT Matrix) Tool as a Strategic Planning and Management Technique in the Health Care Industry and Its Advantages
}

\author{
Ahsan Siddiqui* \\ Quality Management \& Patient Safety Department, General Directorate of Health, Riyadh Saudi Arabia
}

*Corresponding author: Ahsan Siddiqui, Quality Management \& Patient Safety Department, General Directorate of Health, Riyadh Saudi Arabia

\section{ARTICLE INFO}

Received: 慧 November 23, 2021

Published: 㓞 November 29, 2021

Citation: Ahsan Siddiqui. SWOT Analysis (or SWOT Matrix) Tool as a Strategic Planning and Management Technique in the Health Care Industry and Its Advantages. Biomed J Sci \& Tech Res 40(2)-2021. BJSTR. MS.ID.006419.

Keywords: SWOT Analysis; Coronavirus, Strategy; SWOT Analysis Tool; Quality Tools; Quality Management and Patient safety; Health Care Management; Medical Decision-Making; Evidence-Based Medicine; Prevention and Control Management

\section{ABSTRACT}

Background and Objective: The main theme of this article is to discuss the use of SWOT analysis (or SWOT matrix) tool as a strategic planning and management technique in the health care industry and its advantages.

Methods: The Author of this article has chosen literature review methodology of random research articles and literature on the websites regarding SWOT Analysis tool or SWOT Matrix. 15 websites and articles were reviewed for writing article "SWOT analysis (or SWOT matrix) tool as a strategic planning and management technique in the health care industry and its advantages". The literature review has discussed the strengths, weaknesses, opportunities, and threats in details regarding healthcare industry. The SWOT analysis for the health care industry is written in the four tables and then interpreted in the SPSS Diagrammatic presentation.

Results: There are four tables, and four SPSS diagrams represents the SWOT Matrix tool in the healthcare industry. Four tables explain the 6 common Strengths, Weaknesses, Opportunities and Threats for the healthcare industry mentioned in 15 Articles. Four SPSS diagrams show the frequency of SWOT matrix tool of 6 common Strengths, Weaknesses, Opportunities and Threats for the healthcare industry mentioned in 15 Articles.

Conclusion: To sum up, SWOT analysis or SWOT matrix tool is very useful quality management tool for the industry. Strength, weaknesses, opportunities, and threats helps to identify all the characteristics in the organization to start the process of improvement. SWOT analysis tool is infact tool for various industries engineering, defense, aviation, motor, real state, tourism, etc. SWOT tool helps administration to simplify the challenges an organization is facing and would face in the future to write and implement the corrective actions for improvement. SWOT analysis also helps to identify the 7 Muda wastes of the organization to reduce the wastes to make the organization reliable productive and profitable.

\section{Introduction}

The most important strengths of the [1] Department are competent and skilled staff, high quality of services, average hospital bed utilization, the Department providing the educational basis of the School of Medicine, satisfied patients, pleasant setting, and additional working hours. The weaknesses are poor spatial organization, personnel unmotivated to refresh knowledge, lack of specifically trained personnel, inadequate sanitary facilities, and uncovered services by the Insurance Fund, long average hospital stay, and low economic status of patients. The opportunities are 
legislative regulations, formed pediatric traumatology service at the City level, good regional position of the Institute, and extension of referral areas. The threats are absent Department autonomy in the personnel policy of the Institute, competitions within the Institute, impossibility to increase the [1] Department capacities, inadequate nutrition, low opportunities for expert training of the personnel, outdated equipment, and presence of informal payments (Figure 1).

\section{SWOT Analysis}

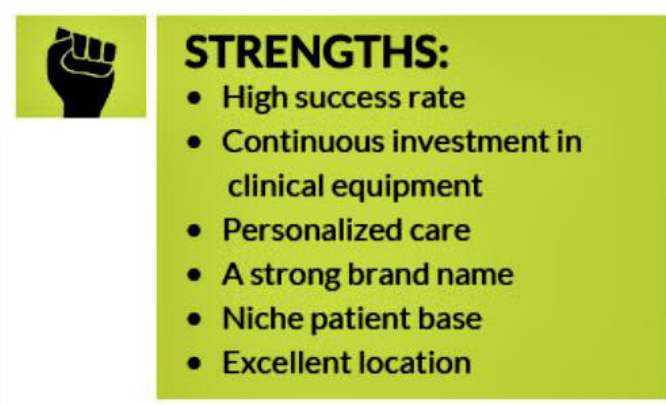

\section{OPPORTUNITIES:}

- Provide diagnostic and lab services to other medical practices

- Attract quality physicians and staff

- Expansionto underserviced areas

- Convenient parking

- Cost-effectiveness

- Successful referral programs with other physicians
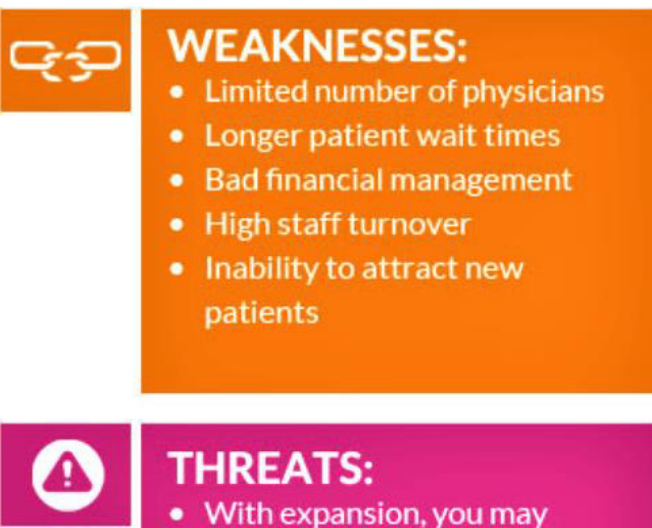

\section{THREATS:}

- With expansion, you may face challenges with patient experience and efficient communication

- Stiff competition

- Staff dissatisfaction

- Security breaches

- Dissatisfied patients

Figure 1: SWOT Analysis in health care [7].

We examined the strengths, [2] weaknesses, opportunities, and threats of implementing a Research Department for the Support of Pediatric Studies (RDPS) in Vienna. We used the SWOT ("strengths", "weaknesses", "opportunities", and "threats") analysis to collect comprehensive data and facts on the internal strengths, weaknesses (company analysis), and external opportunities and threats (environmental analysis). The company analysis revealed a productivity gain, due to a highly specialized team and standardized processes. The environmental analysis outlined a considerable [2] 360-degree potential for a qualitative and quantitative medicaland social-scientific expansion of the service portfolio. The purpose of the research was to [3] investigate the effective sustainable development strategy of home-based exercise in China through a SWOT (Strengths, Weaknesses, Opportunities and Threats) and AHP (Analytic Hierarchy Process) hybrid model. Thirteen factors corresponding to the SWOT analysis were identified through a literature review and expert opinions. The results show that in
China the advantages and potential outweigh the weaknesses and threats of home-based exercise. As the [3] core for the development of home-based exercise this strategy (SWOT) should be given priority.

\section{Methods}

The Author of this article has chosen literature review methodology of random research articles and literature on the websites regarding SWOT Analysis tool or SWOT Matrix. 15 websites and articles were reviewed for writing article "SWOT analysis (or SWOT matrix) tool as a strategic planning and management technique in the health care industry and its advantages". The literature review has discussed the strengths, weaknesses, opportunities and threats in details regarding healthcare industry. The SWOT analysis for the health care industry is written in the four tables and then interpreted in the SPSS Diagrammatic presentation (Figure 2). 


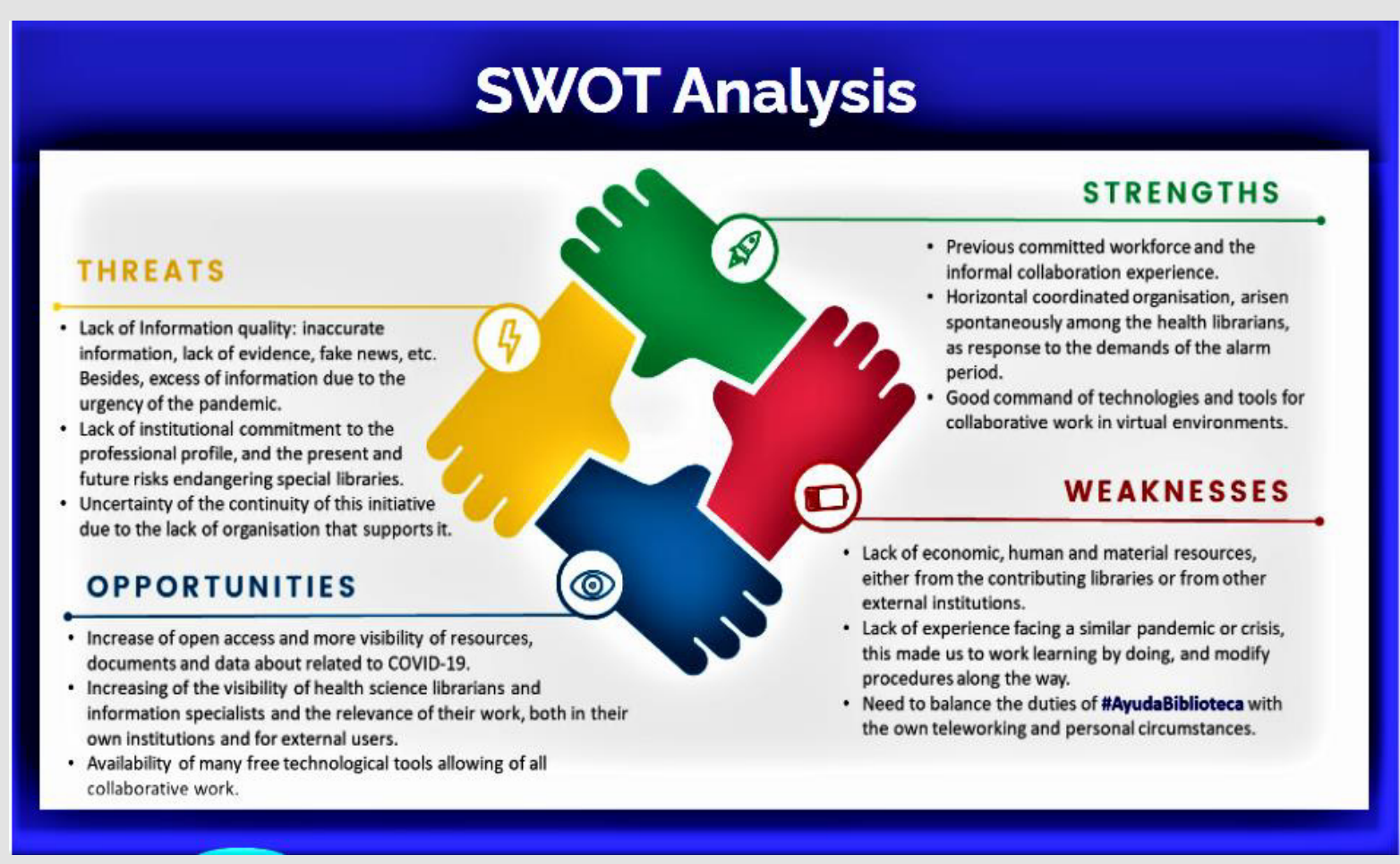

Figure 2: (SWOT analysis AyudaBiblioteca, 2020) [8].

We assessed and formulated (Jia W, Zhifeng W, 2020) strengthopportunity (SO), weakness-opportunity (WO), strength-threat (ST), and weakness-threat (WT) strategies for the prevention and control of the COVID-19 epidemic. We conducted an in-depth analysis and identified the highest priority policies. These are reshaping the emergency system (SO1), adding health emergency departments to universities and other institutions (WO2), adjusting the economic structure and strengthening international and (Jia W, Zhifeng W, 2020) domestic linkages (ST2) and strengthening public intervention in responding to public health emergencies (WT1). We describe four steps of I-SWOT [4] to establish an individualized medical strategy to treat aortic disease. In the first step, we define the goal of therapy and identify all evidence-based therapeutic options. In a second step, we assess strengths and weaknesses of each therapeutic option in a SW matrix form. In a third step, we assess opportunities and threats related to the individual patient and in a final step, [4] we use the I-SWOT matrix to establish an individualized medical strategy through matching "SW" with "OT".

The SWOT analyses draw an overall picture [5] of the complexity of designing and implementing good policies and programs that are tailored to local needs. By March 201614 SWOTs were conducted involving 11 European countries and 57 stakeholders and Ministries of Health, reporting, and analyzing a total of 44 policies. The main strengths, weaknesses, opportunities, and threats have been outlined as well as and the main areas for governance improvement. A binding trans-sectoral [5] approach is necessary to tackle the underlying risk factors of inequalities.

All data were reviewed, arranged into themes, [6] and then categorized either as strengths or weaknesses with respect to addressing the COVID-19 pandemic in dental facilities, and accordingly, threats and possible opportunities to the handling of the pandemic were identified. Preparedness of dental facilities during the current pandemic is a weakness that needs to be addressed promptly. his strengths, weaknesses, opportunities, and threats (SWOT) analysis can be a useful tool for guiding decisionmaking as it is [6] crucial during the current pandemic to work on weaknesses, avoid threats, and utilize all future opportunities.

Measure and Statistical Analysis (Tables 1-4)
(Figures 3-6) $[7,8]$ 
Table 1: 15 WEBSITES \& ARTICLES AGREES THAT 6 COMMON STRENGTHS IN SWOT MATRIX ANALYSIS TOOL.

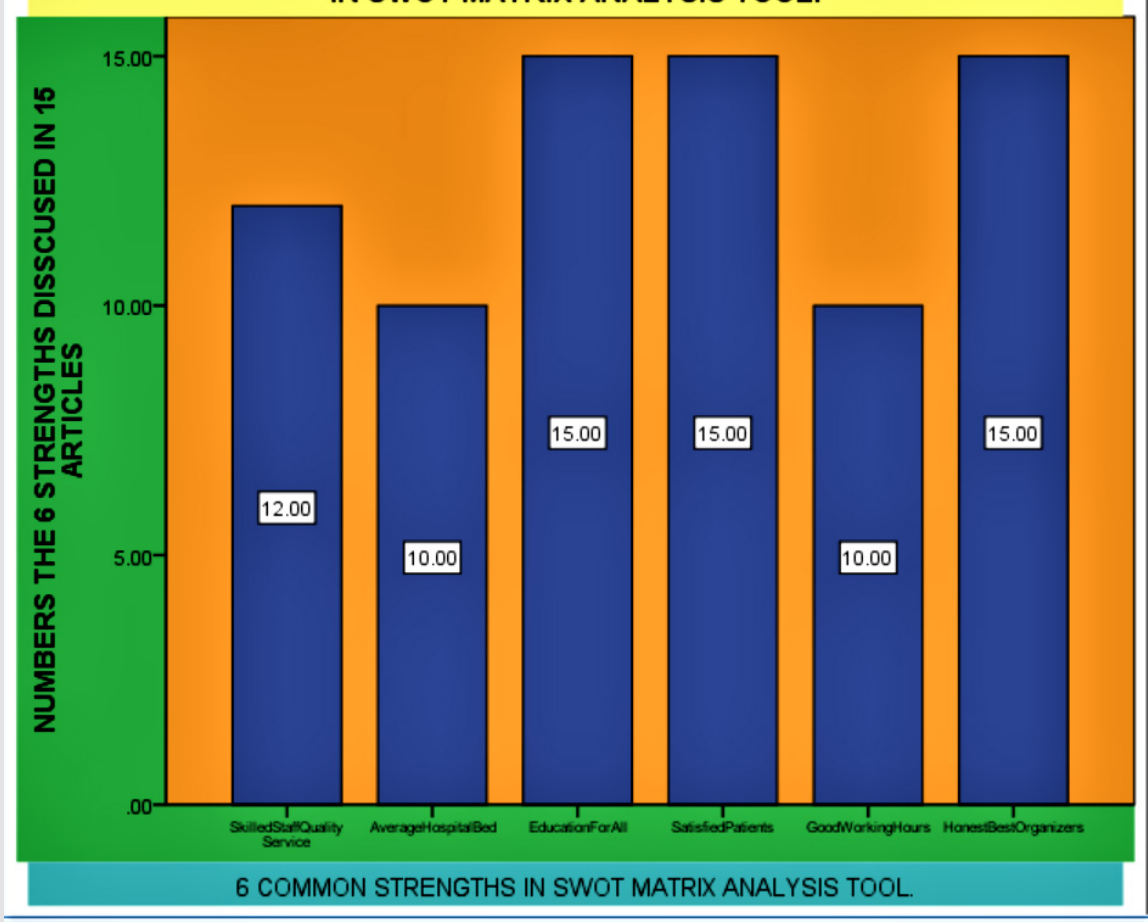

Figure 3: SPSS Diagram regarding showing 15 websites \& articles agrees that 6 common strengths in SWOT matrix analysis tool.

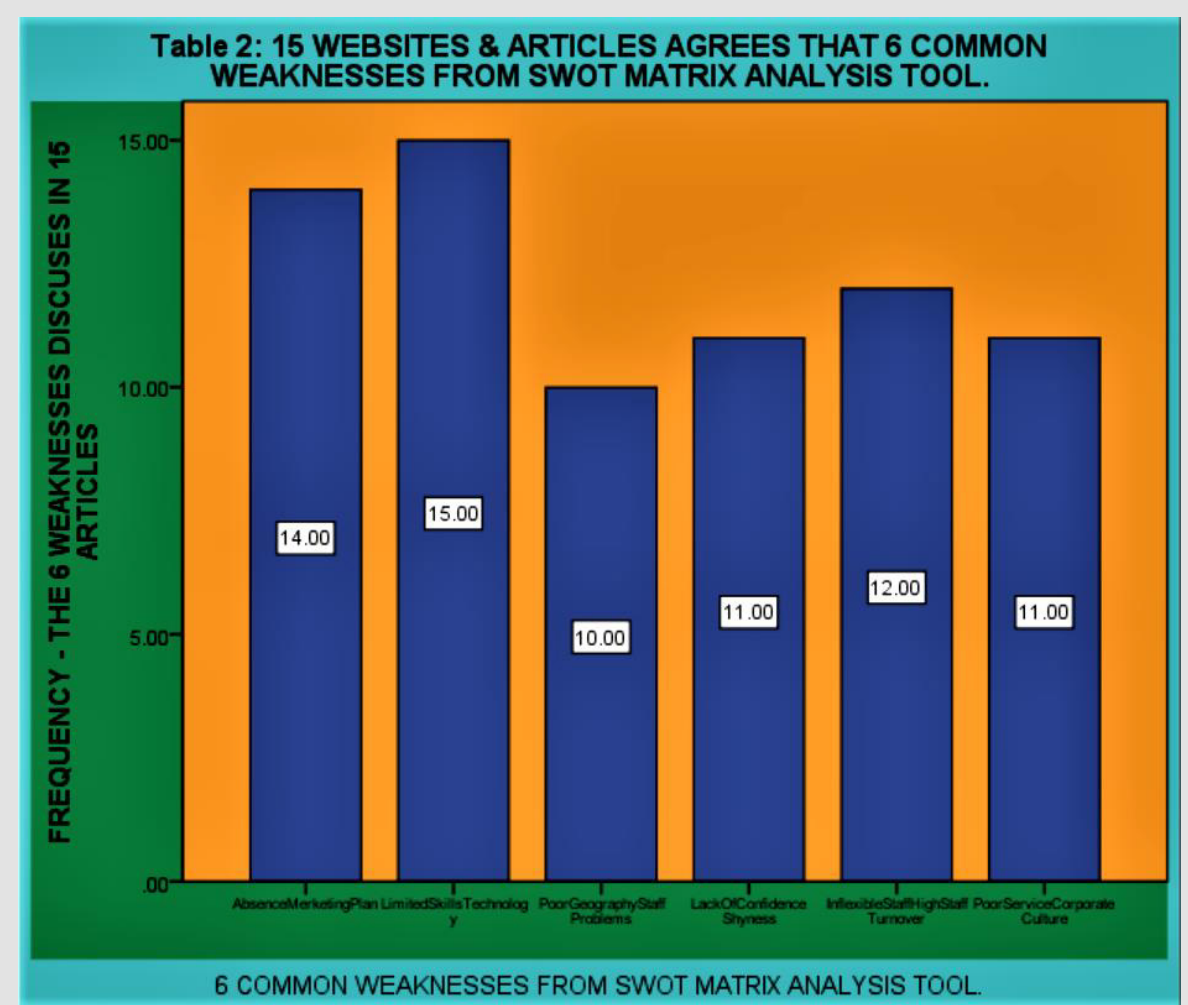

Figure 4: SPSS Diagram regarding showing 15 websites \& articles agrees that 6 common weaknesses from SWOT matrix analysis tool. 


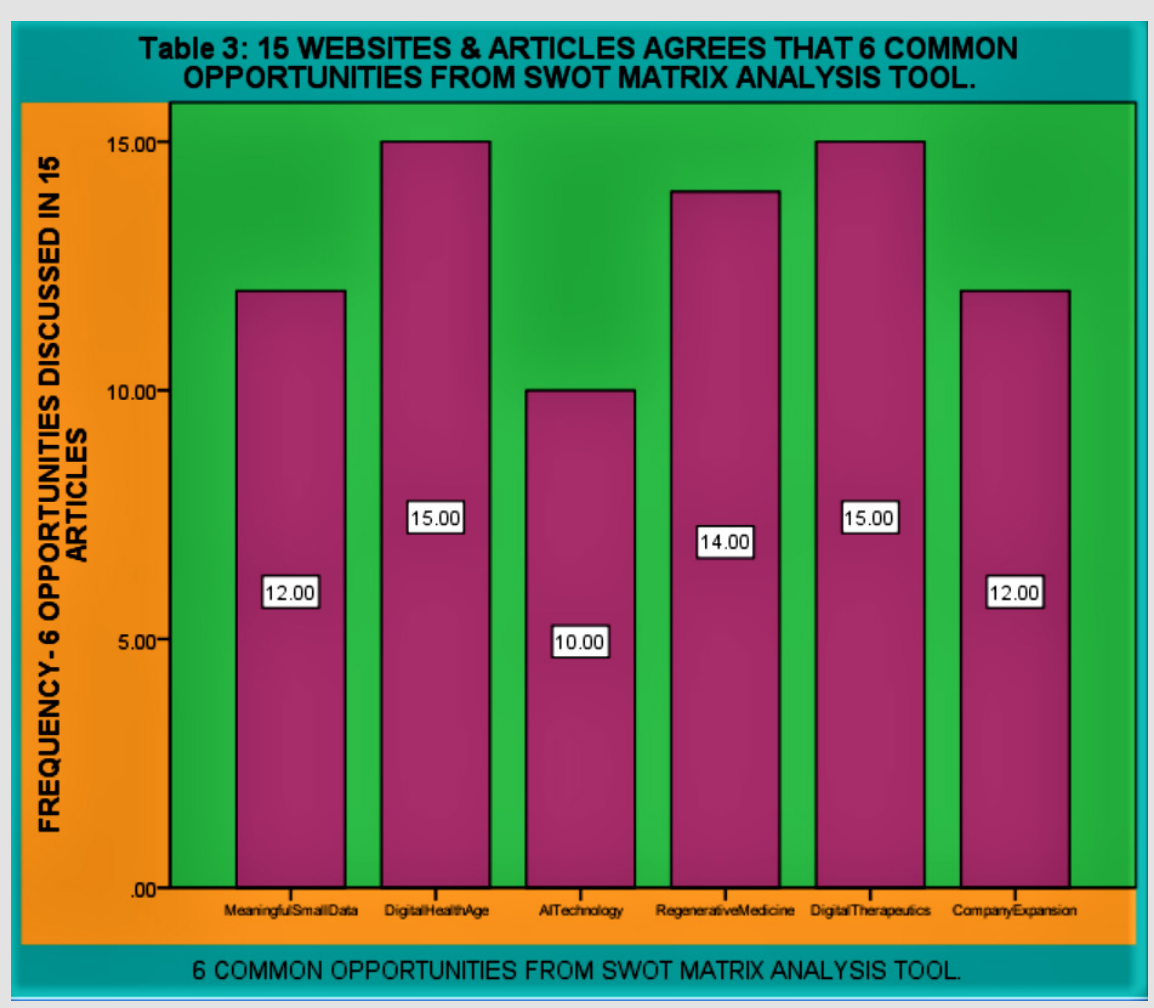

Figure 5: SPSS Diagram regarding showing 15 websites \& articles agrees that 6 common weaknesses from SWOT matrix analysis tool.

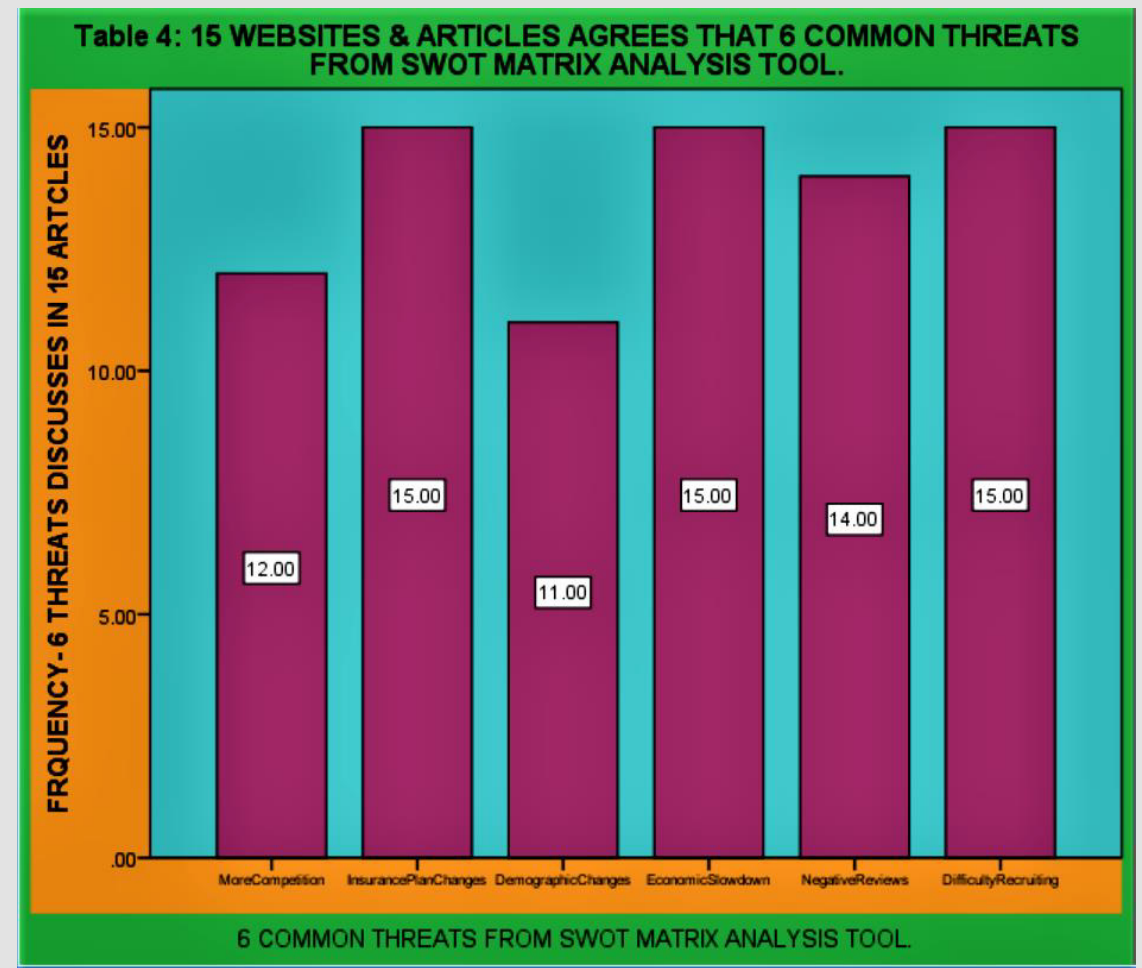

Figure 6: SPSS Diagram regarding showing 15 websites \& articles agrees that 6 common threats from SWOT matrix analysis Tool. 
Table 1: 15 Websites \& Articles Agrees that 6 Common Strengths in SWOT Matrix Analysis Tool.

\begin{tabular}{|c|c|c|}
\hline \multicolumn{3}{|c|}{15 WEBSITES \& ARTICLES AGREES THAT 6 COMMON STRENGTHS } \\
IN SWOT MATRIX ANALYSIS TOOL \\
\hline & Points & Frequency \\
\hline 1 & Competent, skilled staff \& high quality of services. & 12 \\
\hline 2 & Average hospital bed utilization. & 10 \\
\hline 3 & Providing educational bases for all. & 15 \\
\hline 4 & Satisfied patients \& pleasant setting, & 15 \\
\hline 5 & Additional working hours. & 10 \\
\hline 6 & It keeps you honest \& best organizer. & 15 \\
\hline
\end{tabular}

Table 2: 15 Websites \& Articles Agrees That 6 Common Weaknesses from SWOT Matrix Analysis Tool.

\begin{tabular}{|c|c|c|}
\hline \multicolumn{3}{|c|}{15 WEBSITES \& ARTICLES AGREES THAT 6 COMMON WEAKNESSES } \\
FROM SWOT MATRIX ANALYSIS TOOL \\
\hline & $\begin{array}{c}\text { Points } \\
\text { reputation. }\end{array}$ & Frequency \\
\hline 1 & $\begin{array}{c}\text { Absence of marketing plan \& damaged } \\
\text { repres }\end{array}$ & 14 \\
\hline 2 & Limited staff skills, expertise and Technology. & 15 \\
\hline 3 & $\begin{array}{c}\text { Poor location or geographic barriers, staff } \\
\text { problems. }\end{array}$ & 10 \\
\hline 4 & Lack of confidence, shyness, taking criticism. & 11 \\
\hline 5 & $\begin{array}{c}\text { High staff turnover, Inflexible staff, mixed quality } \\
\text { staff. }\end{array}$ & 12 \\
\hline 6 & Poor corporate culture, Poor service levels. & 11 \\
\hline
\end{tabular}

Table 3: 15 Websites \& Articles Agrees That 6 Common Opportunities from SWOT Matrix Analysis Tool.

\begin{tabular}{|c|c|c|}
\hline \multicolumn{3}{|c|}{$\begin{array}{c}\text { 15 WEBSITES \& ARTICLES AGREES THAT 6 COMMON } \\
\text { OPPORTUNITIES FROM SWOT MATRIX ANALYSIS TOOL }\end{array}$} \\
\hline & Points & Frequency \\
\hline 1 & Meaningful small data. & 12 \\
\hline 2 & Digital health coming of age, individual care. & 15 \\
\hline 3 & To bring AI/cognitive platform technology. & 10 \\
\hline 4 & Regenerative medicine. & 14 \\
\hline 5 & Digital therapeutics. & 15 \\
\hline 6 & A company expansion or acquisition. & 12 \\
\hline
\end{tabular}

Table 4: 15 Websites \& Articles Agrees That 6 Common Threats from SWOT Matrix Analysis Tool.

\begin{tabular}{|c|c|c|}
\hline \multicolumn{3}{|c|}{$\begin{array}{c}\text { 15 WEBSITES \& ARTICLES AGREES THAT 6 COMMON THREATS } \\
\text { FROM SWOT MATRIX ANALYSIS TOOL }\end{array}$} \\
\hline & Points & Frequency \\
\hline 1 & New or increased competition. & 12 \\
\hline 2 & Insurance plan changes. & 15 \\
\hline 3 & Adverse demographic changes. & 11 \\
\hline 4 & Economic slowdown, recession. & 15 \\
\hline 5 & Negative customer reviews. & 14 \\
\hline 6 & Staff turnover, difficulty recruiting. & 15 \\
\hline
\end{tabular}

\section{Results}

There are four tables, and four SPSS diagrams represents the SWOT Matrix tool in the healthcare industry. Four tables explain the 6 common Strengths, Weaknesses, Opportunities and Threats for the healthcare industry mentioned in 15 Articles. Four SPSS diagrams show the frequency of SWOT matrix tool of 6 common Strengths, Weaknesses, Opportunities and Threats for the healthcare industry mentioned in 15 Articles. There are countless benefits of conducting a (Unnus.com, 2021) [9] SWOT analysis for your medical business. we'll start by exploring a number of them.

1. SWOT Analysis arms you against future obstacles.

2. It uncovers the untapped opportunities for you to take advantage of.

3. It gets your medical business out of the tunnel vision trap.

4. You can use SWOT Analysis to reverse engineer your competitors. If you are in a competitive environment where the (Unnus.com, 2021) [9] same care facilities are competing for the same patient at the same price SWOT is irreplaceable.

The theme is to discuss and [10] compare the workplace organization method $5 \mathrm{~S}$ with the 7 wastes (Muda) in waste and failure management tool, in the health care quality management. 18 of the articles including the quality management websites agrees on the use of $5 \mathrm{~S}$ and 7 Muda methodology. Different organization around the globe are using $5 \mathrm{~S}$ and 7 Muda methodology to get benefits for improvement of their health care system. The stepby-step process of 5S and 7 Muda methodology is [10] smart way to start, monitor, finish and follow up the broken health system in several countries.

While research in the field of emergency response [11] and more specifically in the field of firefighting is still catching up the future potential of VR technology for training is promising. This paper uses the SWOT framework to analyze the strengths, weaknesses, opportunities, and threats immersive VR technology faces in the field of firefighter training. While using VR for training is cost effective safe to use and provides the ability to prepare trainees with a large variety of high-fidelity training environments, the lack in specialization of the [11] applications for the fire-service sector and issues with technology acceptance and limitations need to be addressed.

Strengths, Weaknesses, Opportunities and Threats (SWOT) [12] analysis enables to identify and assess the strengths and weaknesses within an organization or program, as well as the threats and opportunities outside the given organization or program. To identify SWOT of the HSTP in Iran all articles concerning this program published in scholarly databases as well 
as in the gray literature were systematically searched. Thirty-four subjects expressed comments on classification. Incorporating [12] their suggestions, the SWOT analysis of Iran's HSTP was revised, finalized and then performed.

\section{Discussion}

The SWOT (Strengths, Weaknesses, Opportunities, and Threats) (Bryant Brown healthcare advertising, 2021) analysis has been around since the 1960s. Here are 5 reasons why a SWOT analysis is such a powerful marketing tool.

1. It's the great organizer.

2. It helps you see the big picture.

3. It keeps you honest.

4. It helps you know your competition.

5. It encourages discussion, disagreements and revelations.

After all these years a SWOT analysis for hospitals, pharmaceutical companies, or medical device manufacturers is [13] still a powerful strategic marketing tool. Use it. And strengthen your brand. This SWOT analysis highlights the [14] complex nature of relapse. The results of the SWOT analysis revealed that contextual factors including peer influence, prevalence and availability of MA (Methamphetamine), familiar venue of MA use, discrimination, sexual behaviors, alcohol, emotional states and their attitudes towards smoking MA were important factors that contribute to reinitiating and relapse. Surveillance systems, antidrug social workers, vocational skills trainings, moving to another city and family [14] responsibility might serve as counter measures targeting those mentioned weaknesses and threats above.

We introduced SWOT analysis to 568 medical students [15] during the 2008-2010 academic years, with the objective of becoming "a good physician in the future". Pertinent issues were grouped into 4 categories: not wanting to be a doctor, having inadequate medical professional skills, not wanting to work in rural or community areas, and planning to pursue training in specialties with high salary/low workload/low risk for lawsuit. Further intervention should be [15] considered in order to change the medical student's attitudes on the profession and their impact on Thai health system.

SWOT analysis is helpful in guiding the [16] establishment of a temporary integrated isolation ward and the formulation of prevention and control measures in Hebei General Hospital during the COVID-19 outbreak. It provides the guidance and reference of significance for the establishment of similar types of wards in the future. A total of 93 patients with 18 critically ill patients were admitted for treatment and isolation. Twenty-four supplementary nucleic acid tests were ordered and conducted. One new [16] patient with COVID-19 was confirmed and was successfully transferred to the designated COVID-19 infectious control hospital [17].

\section{Conclusion}

To sum up, SWOT analysis or SWOT matrix tool is very useful quality management tool for the industry. Strength, weaknesses, opportunities, and threats helps to identify all the characteristics in the organization to start the process of improvement. SWOT analysis tool is infact tool for various industries engineering, defense, aviation, motor, real state, tourism, etc. SWOT tool helps administration to simplify the challenges an organization is facing and would face in the future to write and implement the corrective actions for improvement. SWOT analysis also helps to identify the 7 Muda wastes of the organization to reduce the wastes to make the organization reliable productive and profitable.

\section{Conflict of Interest}

No conflict of interest with any institution/organization.

\section{References}

1. Zorica Terzić, Zoran Vukasinović, Vesna Bjegović-Mikanović, Vesna Jovanović, Radmila Janicić (2010) SWOT analysis: the analytical method in the process of planning and its application in the development of orthopedic hospital department. Srp Arh Celok Lek 138(7-8): 473-479.

2. Alexandra T, Margit R, Henriette L (2020) Implementing a Clinical Research Department to Support Pediatric Studies: A SWOT Analysis. Int J Environ Res Public Health 17(17): 6211.

3. Hanming L, Xingquan C, Yiwei F (2021) The Development Strategy of Home-Based Exercise in China Based on the SWOT-AHP Model. Int J Environ Res Public Health 18(3): 1224.

4. Yskert von Kodolitsch, Alexander M Bernhardt, Peter N Robinson, Tilo Kölbel, Hermann Reichenspurner, et al. (2015) Analysis of Strengths, Weaknesses, Opportunities, and Threats as a Tool for Translating Evidence into Individualized Medical Strategies (I-SWOT). Aorta (Stamford) 3(3): 98-107.

5. Angela Giusti, Marina Maggini, Sofia Colaceci (2020) The burden of chronic diseases across Europe: what policies and programs to address diabetes? A SWOT analysis. Health Res Policy Syst 18: 12.

6. Balgis Gaffar, Jehan Alhumaid, Muhanad Alhareky, Faisal Alonaizan, Khalid Almas (2020) Dental Facilities During the New Corona Outbreak: A SWOT Analysis. Risk Manag Healthc Policy 13: 1343-1352.

7. Practice builders SWOT (2017) SWOT Analysis in Healthcare: A SelfExam to Identify Primary Areas of Focus.

8. SWOT analysis AyudaBiblioteca (2020) The initiative AyudaBiblioteca in Spain: A SWOT analysis.

9. Unnus.com (2021) A Step-By-Step Guide To SWOT Analysis In Healthcare.

10. Ahsan Siddiqui (2021) Comparing the Workplace Organization Method 5 s with the 7 Wastes (Muda) in Waste and Fail ᄀure Management Tool, in the Health Care Quality Management. Biomed J Sci \& Tech Res 40(1).

11. Hendrik E, Robert WL, Simon H (2019) A SWOT Analysis of the Field of Virtual Reality for Firefighter Training. Front Robot AI 6: 101.

12. Alireza Olyaeemanesh, Masoud Behzadifar, Nasrin Mousavinejhad, Meysam Behzadifar, Sanaz Heydarvand, et al. (2018) Iran's Health System Transformation Plan: A SWOT analysis. Med J Islam Repub Iran 32: 39. 
13. Bryant Brown healthcare advertising (2021) SWOT Analysis, 5 reasons why healthcare marketers swoon over SWOT.

14. Youwei Zhu, Na Zhong, Hang Su, Xiaolu Ruan, Jiayi Bao, et al. (2019) Strengths, weaknesses, opportunities and threats (SWOT) analysis of reinitiation into methamphetamine abusers: qualitative findings from an exploration of methamphetamine abusers in Shanghai, China. Gen Psychiatr 32(3): e100062.

15. Woratanarat T, Woratanarat P (2012) Assessment of Prospective Physician Characteristics by SWOT Analysis. Malays J Med Sci 19(1): 6064.

ISSN: 2574-1241

DOI: $10.26717 /$ BJSTR.2021.40.006419

Ahsan Siddiqui. Biomed J Sci \& Tech Res

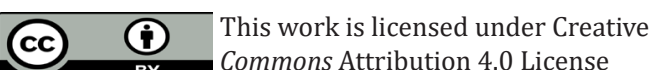

Submission Link: https://biomedres.us/submit-manuscript.php
16. Ye Zhou, Lixiang Bai, Hao Guo, Shaowei Guo, Xiaowen Han, et al. (2021) SWOT Analysis and Preliminary Study on Prevention and Control Management of Temporary Integrated Isolation Ward During COVID-19 Outbreak. Front Public Health 9: 558565.

17. SPSS 20 (2021) IBM SPSS Software.

$\begin{array}{ll}\text { BIOMEDICAL } & \text { Assets of Publishing with us } \\ \text { RESEARCHES } & \text { - Global archiving of articles } \\ \text { - Immediate, unrestricted online access }\end{array}$

